Revista Portuguesa de História

t. XXXII (1997-1998)

\title{
A industrialização da Alta-Estremadura no final do antigo regime - breves notas de investigação
}

SAUL ANTÓNIO GOMES

Universidade de Coimbra

1 - O conhecimento histórico dos quadros económicos e industriais que caracterizaram o País em finais do Antigo Regime tem conhecido, nos últimos anos, um considerável desenvolvimento. Não cumpre arrolar aqui a já numerosa bibliografia publicada sobre o tema'. De um modo geral, os quadros analíticos

Não esquecendo, contudo, estudos marcantes como o de Jorge Borges de Macedo, Problemas de história da indústria portuguesa no século XVIII, Lisboa, 1963 [2." ed. Lisboa, Querco, 1982], a que deveremos juntar os minuciosos estudos de Luís Ferrand de Almeida coligidos na sua obra Páginas Dispersas, Estudos de História Moderna de Portugal, Coimbra, Instituto de História Económica e Social da Faculdade de Letras de Coimbra, 1995. Mais recentemente, a tese de Jorge Miguel Viana Pedreira, Estrutura Industrial e Mercado Colonial. Portugal e Brasil (1780-1830), Lisboa, Difel, 1994. Remetemos para as sínteses sobre esta matéria desenvolvidas por A. H de Oliveira Marques, História de Portugal. Vol. II. Do Renascimento às Revoluções Liberais, Lisboa, Palas Editores, 10." edição, 1984, pp 284-287; Joaquim Veríssimo Serrão, História de Portugal. Vol. VI. O Despotismo Iluminado (1750-1807), Lisboa, Verbo, 1982, pp. 191-205; José Vicente Serrão, "O quadro económico. Configurações estruturais e tendências de evolução", História de Portugal. Vol. 4. O Antigo Regime (Coord. de António M. Hespanha), Lisboa, Estampa, 1993, pp. 89-97. 
entretanto definidos permitiram um maior rigor, na definição da rede cartográfica do fenómeno da industrialização em Portugal nos últimos decénios de Setecentos.

As fontes utilizadas pelos historiadores caracterizam-se, fundamentalmente, por serem produzidas a partir dos centros administrativos da Coroa, traduzindo-se numa tipologia documental composta sobretudo por estatísticas (dentro do rigor que a sociedade intelectual do Antigo Regime lhes conferia), informações, relatórios ou mesmo petições. A estas acrescem os arquivos das próprias fábricas, raros para aquela época, posto que existentes, sobrevivendo a perdas, destruições e dispersões. Uma outra fonte, que aguarda mais atenção por parte dos historiadores deste fenómeno, consiste nos registos notariais depositados por todos os arquivos regionais ou distritais portugueses. Sendo fontes da maior importância na reconstituição das micro-sociedades locais, contém, igualmente, numerosas informações para a temática da história da industrialização portuguesa. Não apresentam estatísticas ou inquéritos oficiais. Mas dão-nos a realidade concreta, de campo, debaixo do prisma da legalidade, que envolvia todo o aparelho económico local e regional. Com bastantes elementos, aliás, inéditos ou mesmo desconhecidos da maior parte dos investigadores. Pelo seu estudo e exame, poderemos, assim sendo, ampliar significativamente os nossos quadros de conhecimento sobre a industrialização portuguesa dos finais do Antigo Regime.

Demonstramo-1o, por exemplo, para o caso da Alta-Estremadura (ou, se se preferir, da antiga Estremadura setentrional), essa mancha industrializada do centro do País que tinha no eixo dos concelhos, com as fronteiras dessa época, de Pombal-Leiria-Alcobaça um dos mais significativos casos de toda a história industrial de Portugal. Não era por acaso, aliás, que na povoação da Marinha, do concelho leiriense até 1918 , se erguia a maior estrutura industrial de todo o País, a famosa Fábrica dos Vidros (que, de John Beare chega aos Stephens) onde laboravam, por 1800,515 operários. ${ }^{2}$

\footnotetext{
Vd. Visconde de Balsemão, "Memoria sobre a descripção física e economica do lugar da Marinha Grande e suas vizinhanças", Memorias Economicas da Academia Real das Sciencias de Lisboa, T. V, Lisboa, 1815, pp. 257-277; Carlos Vitorino da Silva Barros, Real Fábrica de Vidros
} 
2 - 0 período setecentista conheceu, na região alto-estremenha, um surto das actividades oficinais e industriais. Na área das indústrias transformadoras sobressairam os engenhos mecânicos de serração de madeiras, de tecnologia holandesa, utilizados no Pinhal de Leiria em pleno reinado de D. João V(1705$-1750)^{3}$. São famosas as fábricas de vidro, primeiro de John Beare e, mais tarde, dos Stephens na Marinha Grande. A Fábrica destes últimos tornar-se-á mesmo a maior empresa industrial do País no final do século XVIII, empregando mais de trinta mestres distribuídos pelas especialidades de produção de vidro, de vidraça, de serralharia e de carpintaria. A estes somavam-se numerosos oficiais especializados em tarefas manuais como a amassagem de barros, a atiçagem dos fornos ou a minagem das areias finas ${ }^{4}$.

A Real Fábrica do Juncal, fundada em 1770, é um outro caso desta dinâmica económica que a região conheceus. Trata-se de um dos exemplos mais precoces do protagonismo da Alta-Estremadura no desenvolvimento industrial do País. Integrada no sector produtivo cerâmico, a Fábrica do Juncal não só era a maior estrutura do género na região, cerca de 1800 (em torno de Leiria existiam 12 unidades oficinais cerâmicas com 15 operários e em Ourém 5 unidades com 10 operários), como era a única unidade industrial com capacidade produtiva que ultrapassava largamente o consumo dos mercados regionais próximos, sendo as suas louças encaminhadas, via marítima (Porto da Pederneira), quer para as

da Marinha Grande. II Centenário $7769-1969$, Lisboa, Fábrica-Escola Irmãos Stephens, $1969 \quad\left[2 .^{a}\right.$ ed., Leiria, Magno, 1998]; Joaquim Barosa, Memórias da Marinha Grande, Marinha Grande, 3." ed. (preparada por José M. Amado Mendes), Câmara Municipal da Marinha Grande, 1993; Luís Ferrand de Almeida, "A Fábrica de Vidros da Marinha Grande em 1774", Revista Portuguesa de História, T. XVIII (1980), pp. 292-311. José M. Amado Mendes, História da Marinha Grande. Introdução e Perspectivas, Marinha Grande, Câmara Municipal da Marinha Grande, 1993. João Cabral, Anais do Município de Leiria. Vol. III, Leiria, 2." ed., Câmara Municipal de Leiria, 1993, pp. 112-126. Sobre as velha questão das "origens" vidreiras da Marinha, seja-me permitido remeter para o meu estudo: "Nótula Documental Sobre as Origens da Indústria Vidreira na Marinha Grande (1747-1768)", Revista Portuguesa de História, T. XXV (1990), pp. 291-299. (Nestes estudos encontra-se bibliografia mais ampla sobre o tema, que nos dispensamos de citar aqui).

"Vd. Luís Ferrand de Almeida, "O Engenho do Pinhal do Rei no Tempo de D. João V", Revista Portuguesa de História, T. X (1962, pp. 203-256. [Também em Páginas Dispersas..., pp. 1-36].

+ Citado por Jorge M. V. Pedreira, Op. cit. p. 184.

" Maria Filomena Silva Martins, Azulejos do Juncal. Contributo para a história do azulejo em Portugal, Leiria, Diferença, 1937. (Com bibliografia sobre o tema que evitamos repetir aqui). 
Caldas da Rainha e Torres Vedras, quer por via terrestre até à Barquinha, de onde embarcavam Tejo abaixo até Lisboa ${ }^{6}$.

A investigação histórica revela que existiram outras fábricas de manufacturação têxtil e cerâmica de inegável relevância no tecido geo-económico estremenho do pós-1770. Leiria (cidade e concelho onde se integrava a Marinha Grande) e Alcobaça foram os dois pólos primaciais nesta história da indústria nacional. Ambas as cidades e concelhos se afirmaram como núcleos congregadores de elevados investimentos do Erário público e de comerciantes nacionais e estrangeiros, aqui se estabelecendo não só das maiores unidades de produção industrial do País de finais de Antigo Regime, como sobretudo essas unidades se caracterizaram por adoptarem as mais recentes inovações em maquinaria industrial dessa época. Nalgumas dessas fábricas foram aplicados programas de integração dos operários verdadeiramente inovadores para a época, revelando eles não só a actualização dos proprietários e directores ou gerentes dessas indústrias, em termos de organização dos seus estaleiros produtivos, como sobretudo um inegável sentido filantrópico e de humanidade para com os seus trabalhadores.

Foi na Real Fábrica de Lençaria e Algodão de Alcobaça - fundada por uma sociedade mercantil dirigida pelos comerciantes lisboetas André Faria Rocha e António Rodrigues de Oliveira, com um fundo de 52 contos, em parte subsidiado pelo Estado - que funcionou, em 1789, pela primeira vez em Portugal, a máquina industrial jenny, inventada em Inglaterra em 1764, a qual permitia a um só operário pôr em movimento até cem fusos destinados ao fabrico de fio de trama? Esta Fábrica foi uma das estruturas industriais têxteis mais importantes do País em finais de Setecentos. A sua estrutura verdadeiramente empresarial dava trabalho a 36 operários, para os quais foi criado, posto que de aplicação duvidosa, um programa social integrador.

Oriundos de ambientes profundamente rurais, os trabalhadores viam-se constrangidos a um horário e a uma intensidade de trabalho rígidos e nada habituais no trabalho campesino. Cerca de 1800, o director da Fábrica, António

\footnotetext{
' Jorge M. V. Pedreira, Op. cit, p. 123.

'Jorge M. V. Pedreira, Op. cit., pp. 228-229,426.
} 


\section{A industrialização da Alta-Estremadura no final do antigo regime}

Rodrigues de Oliveira, relatava que criara um programa ocupacional para contenção dos operários, à semelhança do executado por Guilherme Stephens na Marinha Grande, do qual constava a realização dejogos ("hum jogo de bola e dois de laranjinha"), nos Domingos e tardes dos Dias Santos, bem como da edificação de um pequeno teatro para distracção: "retirando-os [aos operários] dos vícios, e dos jogos ruinosos a que a mocidade se inclina facilmente, acompanhando com pessoas de máos costumes".

Por 1793, a Real Fábrica de Lençaria e Algodão, então propriedade dos sócios Guillot e Carvalho', renovava os seus estatutos jurídicos, abrindo-se a um significativo investimento de capitais franceses. Nos anos seguintes, à frente da administração desta Fábrica encontram-se franceses, recrutando-se na França de pós-1789 mestres e oficiais especializados em tecelagem e, ao que podemos concluir dos textos documentais, também em estampagem, que para ela vieram laborar. Em 1794, era seu administrador geral Louis Regnault. No ano seguinte, foi contratado para se estabelecer nesta fábrica Louis Chandelier, natural de Rouen (França). ${ }^{10}$ Por essa época, era gestor e director da Fábrica Monsieur Julien Guillot, nela assistente em 1795." Esta estrutura industrial continuava activa em $1796^{12}, 1797^{13}, 1799^{14}$ e em $1800^{15}$, encontrando-se sempre na família Guillot os seus administradores e gerentes.

Segundo o historiador Jorge Pedreira, em 1793, funcionava em Alcobaça um engenho tipo water-frame, com 320 fusos, mas movido por tracção animal. Segundo esse Autor, o: "motor hidráulico entrou em acção [na Fábrica de Alcobaça] em 1796, mas a capacidade do maquinismo fora reduzida para 16 bancas e logo dois anos depois o açude ruiu, prejudicando gravemente o desenvolvimento da fábrica. Assim, em finais do século XVIII, era ainda em

"Jorge M V. Pedreira, Op cit., pp. 406-407.

Arquivo Distrital de Leiria $(=\mathrm{ADL})$ - Reg. Notariais: Maiorga, 2-H-26, fls $12 \mathrm{~V}^{\circ}-19 \mathrm{v}^{\circ}, \quad 56 \mathrm{v}^{\circ}-$ $-59 v^{\circ}$.

${ }^{10}$ A D L - Reg. Notariais: Maiorga, 2-H-27, fls. 19-20v, $67 \mathrm{v}^{\circ}-70 \mathrm{v}^{\circ}$.

$"$ ADL - Reg. Notariais: Maiorga, 2-H-28, fls. 96-99.

${ }^{12}$ A D L - Reg. Notariais: Maiorga, 2-H-30, fls. $106 \mathrm{v}^{\circ}-108 \mathrm{v}^{\circ}, 174 \mathrm{v}^{\circ}-176 \mathrm{v}^{\circ}$.

${ }^{13}$ A D L - Reg. Notariais: Maiorga, 2-H-31, fls. 54-56 ${ }^{\circ}$.

${ }^{14}$ A D L - Reg. Notariais: Maiorga, 2-H-33, fls. $39 \mathrm{v}^{\circ}-43,106 \mathrm{v}^{\circ}-108 \mathrm{~V}^{\circ}$.

${ }^{15}$ A D L-Reg. Notariais:Maiorga, 2-H-34, fls. 97-99. 
Saul António Gomes

Alcobaça que a mecanização estava mais adiantada: além de 28 jennies, trabalhavam cinco máquinas com 204 fusos e uma com 100." ${ }^{16}$ A sua capacidade produtiva permitia-lhe garantir stoks permanentes, abastecendo, sem dificuldade, as necessidades consumistas do mercado nacional, sobretudo ao nível do fornecimento de chitas para estampagem noutras fábricas portuguesas da época. Em 1804, no entanto, a Real Fábrica de Alcobaça, representada por Domingos Teodoro Henriques, contrata-se com Mestre Luca Turreal, genovês, para se passar a manufacturar veludo nas suas instalações. ${ }^{17}$ Isso poderá ser interpretado como significando um sintoma da expansão do negócio e da especialização no fabrico de produtos de consumo destinados às altas hierarquias sociais, no que respeitava a vestuário ou a aprestos de requinte decorativo doméstico, ou aos centros eclesiásticos como fossem igrejas e mosteiros onde se consumia largamente tão precioso tecido nos mais diversificados objectos de culto e de decoração.

Era também em Alcobaça que funcionava, em 1796, uma Fábrica de Aguardente ${ }^{18}$, que ultrapassava largamente, como se infere pelo título, a simples estrutura doméstica oficinal.

O sector têxtil teve na cidade de Leiria um outro núcleo de importante acção. Quer ao nível do algodão, quer ao nível do linho e da lã - e lembraremos aqui a importância dos linhares na região ainda nos inícios do século $\mathrm{XX}^{19}$-, existiam em Leiria boas condições para a manufacturação destas matérias-primas. Era junto de Leiria que funcionava uma pequena fábrica de fiação de algodão cerca de 1800, empregando, no entanto, uns modestos três operários. Em 1791, era proprietário da Fábrica das Fitas de Seda de Leiria o comerciante José Midosi, de origem provavelmente italiana. A sua Fábrica dava emprego essencialmente a mão-de-obra feminina, nela aparecendo, no entanto, como "fabricantes" e "assistentes", estrangeiros como Luigi Rouveri e José Dormand e, ainda, um português de seu nome António Gomes. Sublinhe-se que todos estes inter-

\footnotetext{
'Torge M. V. Pedreira, Op. cit., p. 229.

"ADL - Reg. Notariais: Maiorga, 2-H-34 fls. 149-151v ${ }^{\circ}$.

"A DL - Reg. Notariais Maiorga, 2-H-28, fls. 115-116.

'Vd. Ernesto Veiga de Oliveira, Fernando Galhano e Benjamim Pereira, Tecnologia Tradicional Portuguesa. O Linho, Lisboa, INIC, 1978, passim: João Cabral, Op. cit., Vol. III, pp. 58-60.
} 


\section{A industrialização da Alta-Estremadura no final do antigo regime}

venientes revelam alguma cultura letrada, dominando a escrita e autografando o registo contratual lavrado no cartório notarial de Joaquim António das Neves [Vd. Apêndice, Doc. 1].

Como mestra das aprendizas, José Midosi contratou, naquele ano, uma Luísa Monnet, adobadeira, de origem muito provavelmente francesa, a qual deveria permanecer na empresa durante dois anos a fim de dar: "Liçam e Ensino a todas as Aprendizas da Fabrica com que se poder ocupar; mas no fim do dito tempo só sera obrigada a dar prefeitamente formadas no Trafico da dita Fabrica a duas Aprendizas de sorte que estejam capazes de ficar na dita Fabrica ensinando do mesmo modo que agora fáz a dita Mestra trauzando, e repartindo a seda e tudo o mais que he necessario, e agora se fáz (...)". José Midosi, pelo seu lado, comprometia-se a pagar o alojamento a esta Mestra Adobadeira pagando-lhe 10800 réis por semana. No contrato estabeleceu-se com todo o cuidado o horário de trabalho na Fábrica: "Será obrigada a dita Mestra a assiztir na dita Fabrica todos os dias de trabalho, hem que deveram [principiar] pellas seis horas da Manhãa athé á noutte tirando duas horas cada dia para seu descanso, e pera hir comer; e de Jnverno principiará a horas que bem se veja para trabalhar, e acabará pellas outo horas da noute tirando cada dia outras duas horas". ${ }^{20}$

Por 1801 e 1802, funcionavam na Fábrica de Fitas de Algodão e de Estamparia de Leiria máquinas do tipoflying-shuttle, designadas por "theares de nova invenção", sinal da capacidade de integração das novas tecnologias e maquinarias na actividade produtiva local. Em 1804, Guilherme Peel, referenciado como proprietário desta Fábrica leiriense, enviou um procurador a Inglaterra a fim de que tentasse recrutar cinco mestres ingleses de fiação para virem laborar na oficina leiriense, orientando o trabalho e a maquinaria movida a energia hidráulica que se haveria de adquirir também em solo britânico. Pretendia-se adoptar, muito provavelmente, a water-frame, para que se pudesse laborar: "ao modo Inglez, com engenhos movidos por Agoa, em Fiação, Tecidos, Branquearia, Estamparia e Tinturaria".' A principal dificuldade de Guilherme

\footnotetext{
20 ADL - Reg. Notariais: - Leiria, 9-E-33, fls. 33-33v ${ }^{\circ}$.

$"$ Jorge M. V. Pedreira, Op. cit., p. 217-218, 226, 229-230.
} 
Peel era, no entanto, a do recrutamento de mão-de-obra capaz. Ele considerava a impossibilidade de maiores níveis produtivos devido à: "falta de rapazes [que] tem cauzado hum grande impate, e tem sido a cauza de alguns officiaes que se tem auzentado, estão tão acostumados à ociosidade e mendicancia, que estranhão a disciplina e sugeição de huma Fabrica". Estas dificuldades também foram encontradas nas Fábricas de Tomar, Torres Novas e Alcobaça. ${ }^{22}$

Também existia na cidade de Leiria, em 1802, uma Fábrica de Chapelaria, propriedade de Manuel José da Costa, nela sendo Mestre-sombreireiro António Pereira. Naquele ano, foi efectuado um contrato de aprendizagem do ofício de sombreireiro em favor de Rafael Carreira Gaião, filho do Alferes António Carreira Gaião, naturais do lugar do Telheiro (Leiria), a fim de que, no decurso de quatro anos, fosse ensinado àquele aprendiz tudo: "quanto pertense ao officio de sombreireiro que he lavar Lans, carpiar, cardar, Arcar, vastir, Jmfortir, Tingir, e lustrar e tudo o mais com as circonstancias, e perfeição que se requer que consta de muitas miudezas (...)". [Vd. Apêndice, Doc. 2].

Apesar de se tratar de uma unidade industrial, o sistema de aprendizagem decalcava ainda o costume oficinal doméstico característico do Antigo Regime. O aprendiz começava pelos trabalhos mais indesejáveis e baixos, subindo a pouco e pouco na escala profissional. Ao fim dos primeiros dois anos teria direito a algum vestuário distintivo e, concluída a aprendizagem quadrienal, ascenderia ao posto de oficial sendo-lhe então dado um "vestido" completo.

O aprendiz, enquanto não houvesse outro na Fábrica, seria obrigado: "a varrer as cazas da Fabrica, ferir lume, fazer camas aos officiaes e fazer recados comducentes a mesma Fabrica, e destes somente se lhe dispenssa a obrigação de carretar Agoa, hir ao Assougue buscar carne, ou Peixe e todas as mais obrigaçoens do costume que ha em todas as Fabricas de sombreireiro". Ao Mestre-oficial, além do ensino de todos os segredos da arte, cumpriria lançar nas: "folhas semanarias da dita Fabrica ou declarar a quem as escreva quanto se deve lançar nas mesmas folhas que são despezas e Jornais diarios dos officiaes e Aprendizes e destes explicará em que se ocuparão e a quantidade que fizerão 
de chapeos para asim se conheser e contar a obrigação a que cada hum faltou em os dias de cada semana e para nam poderem alegar duvidas asignaram a dita folha (...)". Ao proprietário da Fábrica cumpriria dar-lhe sustento de: "cama e Meza como he custume nas ditas Fabricas e igualmente se obrigava a dar lhe dous vestidos como he uzo das ditas Fabricas que consta no meio do tempo que he aos dous annos por huns calçoens de Tripe em dinheiro mil e outocentos reis, e no fim do tempo que he aos quatro annos o segundo e ultimo vestido que consta, Por uns çapatos seiscentos reis, Por hum Par de Meias quatrocentos e outenta reis,, Por huns calçoens de Tripe mil e outocentos reis,, Por hum Collete de Baeta seiscentos reis, por huma veste de Pano fino dous mil e quatrocentos reis,, Por humas fivellas duzentos e quarenta reis,, Por uma camiza seiscentos reis,, Por huma gravata duzentos e quarenta reis,, Por hum chapeo seiscentos reis,, Por hum capote sinco mil reis".

Uma outra Fábrica de Chapéus, bem mais conhecida do que a pequena unidade leiriense, em parte devida ao investimento e proteccionismo da Coroa, foi a Real Fábrica de Chapéus Finos da Quinta da Gramela, em Pombal, de que erajuiz conservador, em 1771, o Dr. Constantino Barreto de Sousa, ouvidor e juiz dos órfãos daquela vila, bem como do Desembargo de Sua Majestade. ${ }^{24}$ Foi nela que se iniciou, decerto sob orientação dos franceses Fournol, mais arde fundadores de outras fábricas de chapelaria em Abrantes e no Porto, a utilização das peles de coelho e de castor na confecção de chapéus que tinham larga aceitação no mercado nacional e colonial. ${ }^{25}$

Eram mais frequentes, na região alto-estremenha, as oficinas para-industriais de curtumes (sete em Leiria para 19 operários), uma em Alcobaça para 17 trabalhadores, oito em Ourém para 33 oficiais de serviço. ${ }^{26}$ Eram também significativas as olarias (12 em Leiria para 15 serventuários), 5 em Ourém (para um total de 10 operários) e uma outra, também na região, com 14 trabalhadores.

Os lanifícios tradicionalmente produzidos em Minde e em Mira de Aire -

${ }^{23}$ ADL - Reg. Notariais: Leiria, 9-E-41, fls. 244-245.

${ }^{24}$ A D L - Reg. Notariais: Leiria, 9-E-13, fls. $144 \mathrm{v}^{\circ}-149 \mathrm{v}^{\circ}$.

Jorge M. V. Pedreira, $O p$ cif., pp. 280, 426-427.

${ }^{26}$ Jorge M. V. Pedreira, Op. cit., p. 104. 
com fama que atinge o pleno século XX - não acompanharam, no entanto, este processo de desenvolvimento tecnológico protagonizado pelas fiações de Alcobaça e de Leiria. ${ }^{27} \mathrm{Na}$ Serra de Aire, efectivamente, não se processou a implantação de novos métodos de trabalho, permanecendo activos os ancestrais hábitos de serviço oficinal doméstico, longe, por isso mesmo, da concentração de maquinaria e do desenvolvimento de actividades especializadas de manufacturação. Em Minde ou em Mira de Aire o processo de fabrico de mantas e outros lanifícios permaneceu agarrado às estruturas oficinais rurais, em que a tecelagem e a tinturaria se executavam nos intervalos do trabalho rural e como complemento económico do agregado familiar. O camponês nunca se tornou verdadeiramente operário.

3 - Pelos elementos apresentados, verifica-se a importância dos quadros estrangeiros na implementação da industrialização regional alto-estremenha. Como, aliás, em toda a mancha industrial portuguesa. A história destes "imigrantes" espera também os seus estudiosos. Mas poderemos referenciar, desde já, que outros estrangeiros houve que tiveram interesses económicos na região.

Em 1736, assistia no Engenho da Marinha [Grande] o Engenheiro João de Vitte. ${ }^{28}$ Mais tarde, encontramos entre os proprietários da região pessoas como Anthony Plomer, britânico, residente no Casal da Lebre (Mouta, c. Leiria), autor de uma doação a Anastácia Maria, casada com Ezequiel de Sousa, filha de Maria Teresa, do lugar do Souto da Carpalhosa, em favor de duas crianças, António Plomer e Teresa Maria. ${ }^{29}$ Britânico era também William Stephens, o

27 Vd. António Martins Cacela, Porto de Mós e seu Termo, Torres Novas, [ed. do Autor], 1977, pp, 195-200 et passim.

${ }^{2 s}$ A D L - Reg. Notariais: Leiria, 9-D-8, fls. 168-168 ${ }^{\circ}$.

29 "Em razão de ter sido sua criada tratando o nesse tempo com todo o desvello, engomandolhe a sua roupa, tratando o nas suas infirmidades no que teve hum grande trabalho, e alem disso pela maior razão de terem estes em sua caza hum menino por nome Antonio Plomer a quem ama e estima elle Doante como filho, por cuja razão de sua propria e Livre vontade, e em remuneração dos referidos serviços, e especialmente para o fim da criação do dito menino, pela presente espriptura e na melhor forma que em Direito lugar haja, lhe dá, e doa o uzufruto de huas Cazas com seo serrado e com todas as suas serventias e logradouros no lugar da Mouta de Baixo (...) e Thereza 
famoso proprietário da Fábrica de Vidros da Marinha, localidade onde residia. ${ }^{3}$ Era também o caso de D. Helena Tudejer, viúva de Thomas Tudejer, inglês, com residência em Lisboa no ano de 1797, detendo, no entanto, propriedades na zona de Alcobaça. ${ }^{31}$

Entre os franceses, para além dos mencionados comerciantes e industriais proprietários de fábricas em Leiria ou em Alcobaça, citaremos os casos de Monsieur Francisco Luis Faget, assistente na Quinta da Madalena (Leiria), por 1798 e 1802. Seria porventura de nação francesa, o Barão de Roset, com propriedades próximas também da Quinta da Madalena (Leiria). ${ }^{32}$ Um outro ilustre proprietário leiriense, era Reinaldo Oudinot, Sargento-mor de Infantaria "com exercício de Engenheiro", assistente em Vieira de Leiria, em 1781, e, mais tarde, proprietário da Quinta da Ponte da Pedra (Regueira de Pontes) (1799$-1802) .^{33}$

Nomeia-se entre outros nomes estrangeiros, ou descendentes destes, o de D. Maria Violante da Mota Velasquez Sarmento, proprietária da Quinta de Ulmar ou do Rio (freg. ${ }^{a}$ Monte Real), viúva de António Osório Cabral de Pina e Melo e cunhada de D. Rita Osório Cabral de Pina e Melo (1794 e 1799). ${ }^{34}$ Foi depois das Invasões Francesas, como se sabe, que alguns outros estrangeiros se fixaram na região dando origem a famílias de prestígio. ${ }^{35}$ Algumas dessas famílias tornarse-ão responsáveis, ao longo dos séculos XIX e XX, pelo surto industrial que a região protagoniza no Portugal contemporâneo.

\footnotetext{
Maria que se está criando em caza de Joaquim Jorge da Mouta de Riba, aos quais tem tanto amor Como se fossem seos filhos proprios" (ADL-Reg. Notariais: Batalha, 5-G-21, fls. 114-115v ${ }^{\circ}$.

${ }^{10}$ A D L - Reg. Notariais: Leiria. 9-E-39, fls.133-134v .

"A DL - Reg. Notariais: Maiorga, 2-H-31, fls. $41-44$

${ }^{32}$ ADL - Reg. Notariais: Leiria. 9-E-39, fls. 139v ${ }^{\circ}-140 ; 9-E-41$, fls. $264 v^{\circ}-265$.

${ }^{33}$ A D L - Reg. Notariais: Leiria. 9-E-24, fls. 131v ${ }^{\circ}-134 ; 9-E-38$, fls. 55-55v ; 9-E-40, fls. 44$45 v^{\circ}, 54-54 v^{\circ} ; 9-E-41$, fls. $24-25 v^{\circ}$.

${ }^{34}$ A D L - Reg. Notariais: Leiria, 9-E-36, fls.19v ${ }^{\circ}-22 ; 9-E-40$, fls. $105 v^{\circ}-107$.

s O caso mais conhecido é o da família Charters. Mas outras há menos conhecidas como acontece com os Suordem, da zona da Calvaria (c. Porto de Mós), étimo derivado do inglês "sword" (espada), em referência ao soldado inglês que decidiu instalar-se na região. É uma história ainda por fazer...
} 


\section{APÊNDICE DOCUMENTAL}

Doc. I

1791, Janeiro, 19, Leiria - Contrato feito entre José Midosi, proprietário da Fábrica das Fitas, de Leiria, e Luísa Monnet, adobadeira, para ensinar todas as aprendizas da Fábrica, por dois anos, pelo preço de dez mil e oitocentos réis semanais.

Arq. Distr. de Leiria - Reg. Notariais: Leiria, 9-E/33, fls. 33-33v ${ }^{\circ}$

\author{
$\mathrm{D}$ (istribuid)a $\mathrm{fl.65 \textrm {v } ^ { \circ }}$ \\ F(ora) 2 .
}

Escriptura de contracto e ajuste que fazem Joze Midosi Proprietario da Fabrica das fitas desta cidade de Leyria e Luiza Monnet Adobadoira da dita Fabrica,

Saibam Quantos Este publico Jnstromento de Carta de contracto e ajuste e convençam ou como em Direito mais valido seja e dizer se possa virem que sendo no Anno do Nascimento de Nosso Senhor Jehsus Christo de mil setecentos e noventa e hum annos aoz dezanove dias do mes de Janeiro do ditto anno nesta cidade de Leyria e cazas de morada de Jozé Midosi Proprietario das Fitas desta mesma cidade ahy foram prezentes de huma parte o dito Joze Midosi pessôa que Eu Tabeliam conheço, e de outra Luiza Monnet Adobadoira da ditta Fabrica, pessôa conhecida das Testemunhas ao diante nomiadas e asignadas, e por elles ambos junctamente e cada hum de per sy me foy ditto perante as mesmas Testemunhas que era verdade que elles entre sy por este publico Jnstromento estavam ajustadas, e convencionados com as condicoens // (F1.33v $\left.{ }^{\circ}\right)$ Com as Condicoens seguintes, as quais ambos prometem dar cumprimento a saber:

Promette a ditta Luiza Monnet que se nam Auzentará da ditta Fabrica antes de acabar o tempo convencionado de dois annos consequtivos, que principiarão no primeiro de Janeiro deste presente anno de mil setecentos noventa e hum, e findarám no ultimo dia do més de Dezembro de mil setecentos noventa e dois:

E promette elle ditio Jozé Midosi de a nam despedir antes do dito tempo, e só por cauza necessaria, ou Razam sufficiente arbitrio de Julgador se poderá hir contra o que se ajusta a este respeito:

Será obrigada a trabalhar no dito tempo dando Liçam, e Ensino a todas as Aprendizas da Fabrica, com que se poder ocupar; más no fim do dito tempo só será obrigada a dar prefeitamente formadas no Trafico da dita Fabrica a duas Aprendizas de sorte que estejam capazes de ficar na dita Fabrica ensinando do mesmo modo que agora fáz a dita Mestra trafuzando, e repartindo a seda e tudo o mais que he necessario, e agora se fáz; porem 
huma das duas Aprendizas estará perfeita sómente no trafuzar thé ao més de Junho deste anno de mil setecentos noventa e hum:

Será obrigado o dito Outorgante Joze Midosi pagar á dita Mestra todos os mezes Por todo o dito Tempo dos dois annos a dés mil e outoCentos reis semanais sem outra condiçam dando lhe Quarto para assistir em todo o tempo à custa do dito Jozê Midosi:

Será obrigada a dita Mestra a assiztir na dita Fabrica todos os dias de trabalho hem que deveram pellas seis horas da Manhãa athé á nouthe tirando duas horas cada dia para seu descansso, e para hir comer; e de Jnverno principiará a horas que bem se veja para trabalhar, e acabará pellas outo horas da noute tirando cada dia outras duas horas;

E nesta forma disseram elles dittos Outorgantes estauam ajustados e contratados, e queriam que esta escriptura valese como nella se conthem, e na milhor forma que o Direito permitte, e ambos ${ }^{\mathrm{a}}$ a aceytauam, e se obrigauam a todas as clauzolas e condicoens delia. E em fe e testemunho de verdade assim o disseram e outorgaram e mandaram fazer este publico Jnstromento nesta Notta e delia dar os traslados necessarios que cumprirem deste Theor que aceytaram e Eu Tabeliam pellos auzentes a que tocar possa quanto o Direito me permite e foram Testemunhas a tudo prezentes perante as quais esta por mim lhes foj lida e que com elles aqui asignaram. Joze Dormand assistente na dita Fabrica que asignou a Rogo da Outorgante e Luiz Rouveri e Antonio Gomes ambos Fabricantes da mesma Fabrica. Joaquim Antonio das Neues publico Tabeliam de Nottas que o Escrevi. E declaro que diz a entrelinha na primeira lauda regras seis $=$ da Fabrica $=0$ sobredito o declarei.

a) Joze Midosi.

a) Rogo da subreDitta: Jozé Dormand

a) Luigi Roueri.

a) Antonio Gomes. // 


$$
\text { Doc. } 2
$$

1802, Janeiro, 25, Leiria - Contrato estabelecido entre Rafael António Gaião, do Telheiro (c. Leiria), e António Pereira, mestre sombreireiro da fábrica de Chapéus de Manuel José da Costa, de Leiria.

Arq. Distr. de Leiria - Reg. Notariais: Leiria, 9-E/41, fls.244-245

F(ora) 1 - Escritura de comtrato e obrigaçam que fazem Rafael Antonio Gaião com autoridade de seu Pay o Alferes Antonio Carreira Gaião e como Fiador do dito seu filho ambos do lugar do Tilheiro termo desta cidade com Antonio Pereira Mestre sombreireiro da Fabrica da chapeos de Manuel Joze da Costa da mesma cidade, e com o dito Manuel Joze da Costa.

Saibão quantos este Publico Jnstromento de Carta de comtrato e obrigação virem que no Anno do Nascimento de Nosso Senhor Jezus Christo de mil outocentos e dous annos aos vinte e sinco dias do mes de Janeiro do dito anno nesta cidade de Leiria e cazas de morada de mim Tabeliam ao diante nomeado ahi sendo prezentes Antonio Pereira Mestre sombreireiro da Fabrica de chapeos de Manuel Joze da Costa Dono da dita Fabrica, e Rafael Antonio Gaião e seu Pay o Alfferes Antonio Gai digo Antonio Carreira Gaião do lugar do Tilheiro termo da dita cidade todos pessoas conhesidas de mim Tabeliam e das Testemunhas abaixo asignadas ahi pelo dito Mestre Antonio Pereira me foi dito perante ellas que por este // $\left(\mathrm{F} 1.244 v^{\circ}\right)$ Este Publico Jnstromento de sua livre vontade tinha ajustado com o dito Manoel Antonio Gaião com autoridade de seu Pay o Alfferes Antonio Carreira Gaião de o emsinar no officio de sombreireiro e a po 110 promto e perfeito no dito officio no decursso de quatro annos com as comdiçoens e obrigaçoens,.

Que o dito Aprendis será obrigado a estar as ordens do dito seu Mestre para este lhe emsinar quanto pertense ao officio de sombreireiro que he lavar Lans, carpiar, cardar, Arcar, vastir, Jmfortir, Tingir, e lustrar e tudo o mais com as circonstancias, e perfeição que se requer que consta de muitas miudezas e isto no dito espasso de quatro annos,,

Que o dito Aprendis alem do que pertense ao dito officio e emquanto não houver outro Aprendis será obrigado a varrer as cazas da Fabrica, ferir lume, fazer camas aos officiaes e fazer recados comducentes a mesma Fabrica, e destes somente se lhe dispenssa a obrigação de carretar Agoa hir ao Assogue buscar carne, ou Peixe e todas as mais obrigaçoens do custume que ha em todas as Fabricas de sombreireiro,, 
Que o dito Aprendis fica (e) ficará obrigado a cumprir todas as referidas comdiçoens sem alegar impossibilidade athe completar o Numero dos ditos quatro annos porque os dias que faltar na dita Fabrica por culpa, omição, ou molestia ha de compor e os dias que trabalhar e não fizer a obrigaçam de quantidade e bondade que lhe compette ao tempo que fizer as faltas da mesma forma lhe seram com todas para as compor por sua pessoa ou por seus bens ou de seu fiador:

E pello dito Mestre foi mais dito que elle se obrigava por sua pessoa e por todos os seus bens a emsinar o dito Aprendis com bom modo sem lhe ocultar ao tempo devido quanto lhe deve emsignar, e que tambem se obriga a fazer todas as folhas semanarias da dita Fabrica ou declarar a quem as escreva quanto se deve lançar nas mesmas folhas que sao despezas e Jornaes diarios dos officiaes e Aprendizes e destes explicará em que se ocuparão e a quantidade que fizerão de chapeos para asim se conheser e contar a obrigação a que cada hum faltou em os dias de cada semana e para nam poderem alegar duvidas asignaram a dita folha e pello sobredito Manuel Joze da Costa Dono da dita Fabrica foi dito que elle se obrigava pellos seus bens a sustentar o dito Aprendis de cama e Meza como he custume nas ditas Fabricas e igualmente se obrigava a dar lhe dous vestidos como he uzo das ditas Fabricas que consta no meio do tempo que he aos dous annos por nuns calçoens de Tripe em dinheiro mil e outocentos reis,, por hum collete de baeta seiscentos reis,, por huma veste de Pano fino dous mil: e quatrocentos reis, Por huma camiza seiscentos reis, e no fim do tempo que he aos quatro annos o segundo e ultimo vestido que consta,, Por huns çapatos seiscentos reis,, Por hum Par de Meias quatrocentos e outenta reis,, Por huns calçoens de Tripe mil e outocentos reis,, Por hum Collete de Baeta seiscentos reis,, por huma veste de Pano fino dous mil e quatrocentos reis,, Por humas fivellas duzentos e quarenta reis,, Por huma camiza seiscentos reis,, Por huma gravata duzentos e quarenta reis,, Por hum chapeo seiscentos reis,, Por hum Capote sinco mil reis,

E promete o Dono da dita Fabrica ao dito Aprendis que fazendo este bem as suas obrigaçoens // (Fl. 245) obrigaçoens de forma que pellas folhas semanarias conste, perdoar lhe alguns Mezes dos ditos quatro annos comforme lhe achar merecimentos e no Cazo de faltar o dito Mestre Antonio Pereira que agora asigna a sua obrigacam obriga se tambem elle dito Dono da Fabrica a apromtar outro Mestre para o emsinar na mesma Fabrica e sendo incomveniente a comservação da dita Fabrica ou duvidoso achar Mestre para ella lhe procurará Mestre em outra terra para acabar o tempo de quatro annos de emsino e isto como deve ser:

E pello dito Aprendis Rafael António Gaião me foi dito que pella autoridade que tinha alcançado de seu Pay se sugeitava a todas as comdiçoens desta escritura no referido tempo do(s) ditos quatro annos e aprehender quanto pudese as suas obrigaçoens pela sua 


\section{A industrialização da Alta-Estremadura no final do antigo regime}

pessoa e toda a perda e damno que cauzase pella falta das suas obrigaçoens E para maior segurança pello sobredito Alferes Antonio Carreira Gaião Pay do referido Aprendis foi dito que elle tinha dado outoridade ao dito seu filho para se poder obrigar a todas as comdiçoens desta escritura e que era comtente em ser fiador abonador e principal pagador de toda a perda ou damno que o dito seu filho podese cauzar a dita Fabrica ou ainda pella perda da falta das suas obrigaçoens aqui referidas ao que obrigava sua pessoa e todos os seus bens moveis e de rais havidos e por haver dando porem o sobredito Mestre da Fabrica, e Dono delia inteira satisfação ao prometido nesta Escritura e outrosim mais foi declarado que o dito Aprendis se lhe principiou a contar o tempo dos referidos quatro annos do seu emsino em o primeiro dia do mes de Janeiro deste prezente anno E em fe e testemunho de verdade assim o diserão e outorgaram e mandarão fazer este Publico Jnstromento nesta Notta que aceitaram eu Tabeliam pellos auzentes quanto o Direito me permite sendo a tudo Testemunhas prezentes perante as quaes esta por mim lhe foi lida que todos aqui asignaram Joaquim Antonio Pereira desta cidade e Manoel Ferreira do lugar do Tilheiro termo da mesma e eu Joze de Mattos Falcam e Faria Publico Tabeliam de Nottas que o escrevy.

a) Manoel Joze da Costa.

a) Antonio Carreira Gayam.

a) Joaquim Antonio Pereira.

a) Antonio Pereira.

a) Rafael Antonio Gaiam.

a) Manoel Ferreira. // 